\title{
$\mathrm{SiOCH}$ 박막의 열처리에 따른 전기적인 특성
}

\section{Electrical Properties of SiOCH Thin Films by Annealing}

\author{
김민석 ${ }^{1, a}$, 황창수 $^{2}$, 김홍배 $^{3}$ \\ (Min-Seok Kim ${ }^{1, a}$, Chang-Su Hwang ${ }^{2}$, and Hong-Bae Kim
}

\begin{abstract}
The SiOCH films that low dielectric interlayer dielectric materials were deposited on p-type Si(100) substrates through the dissociation of BTMSM precursors with oxygen gas by using PECVD method. BTMSM precursor was introduced with the flow rates from $42 \mathrm{sccm}$ to $60 \mathrm{sccm}$ by $2 \mathrm{sccm}$ step in the constant flow rate of $60 \mathrm{sccm} \mathrm{O}_{2}$. SiOCH thin films were annealed at $450{ }^{\circ} \mathrm{C}$ for 30 minutes. The electrical property of $\mathrm{SiOCH}$ thin films was studied by $\mathrm{MIS}, \mathrm{Al} / \mathrm{SiOCH} / \mathrm{p}-\mathrm{Si}(100)$, structure. Annealed samples showed even greater reductions of the maximum capacitance and the dielectric constant of the $\mathrm{SiOCH}$ samples, owing to reductions of surface charge density. we confirmed this result with derivative of $\mathrm{C}-\mathrm{V}$ characteristic, leakage current density. The maximum capacitance and leakage current density were respectively decreased about $4 \mathrm{pF}, 60 \%$ after annealing. The average of low $-\mathrm{k}$ value is approximatly 2.07 after annealing.
\end{abstract}

Key Words : $\mathrm{SiOCH}, \mathrm{C}-\mathrm{V}$ characteristic, Flat-band voltage, Leakage current

\section{1. 서 론}

반도체 소자가 초대규모집적회로 (ULSI)로 발전 하면서 chip 크기도 계속해서 축소하는 추세이다. 그에 따라 트랜지스터들 사이에 기본소자의 크기가 지속적으로 감소하고, 복잡한 다층배선구조로 밀집 하면서 기생결합효과 (parasitic coupling effect) 문제가 발생하였다. 이러한 효과는 $\mathrm{RC}$ 시간지연 (RC delay time)의 증가와 신호간섭 (cross talk noise)을 발생시키고 전력손실 (power dissipation) 증가와 같은 문제를 발생시켜 고속화에 장애요인 이 되고 있다[1].

현재에 사용되고 있는 $\mathrm{Al} / \mathrm{SiO}_{2}$ 층간 절연막은 집적회로의 배선 간격이 $650 \mathrm{~nm}$ 에서 $100 \mathrm{~nm}$ 로 감

1. 청주대학교 전자공학과

(충북 청주시 상당구 내덕동 36 )

2. 공군사관학교 물리학과

3. 청주대학교 전자정보공학부

a. Corresponding Author : gemin7@ naver.com

접수일자 : 2008. 10. 24

1차 심사 : 2008. 11. 17

심사완료 : 2008. 11. 21
소함에 따라 $\mathrm{RC}$ 시간지연이 $2 \mathrm{ps}$ 에서 $38 \mathrm{ps}$ 로 빠 르게 증가하여 고속화에 대한 장애요인으로 대두 되고 있다[2]. 따라서 이러한 소자의 성능을 개선 하기 위해 현재 사용되고 있는 $\mathrm{Al}$ 배선을 전기저 항이 낮은 $\mathrm{Cu}$ 배선으로 교체하는 것과, 배선 사이 의 정전용량을 줄이기 위해 저유전상수를 갖는 새 로운 층간 절연막 (Interlayer Dielectric)으로 대체 하는 것이 필수적으로 요구되고 있다[3].

특히 여러 가지 저유전물질 중에서도 $\mathrm{SiO}_{2}$ 박막 의 특성을 그대로 가지고 있으면서 저유전상수를 갖는 $\mathrm{SiOCH}$ (Siliconoxycarbides) 박막에 대한 연 구가 활발하게 이루어지고 있다[4]. $\mathrm{SiOCH}$ 는 다량 의 탄소가 포함되어 있는 하이브리드 (hybrid type) 특성의 저유전상수를 갖는 물질로써 $\mathrm{Si}-\mathrm{CH}_{3}$ 형태의 낮은 이온 분극성 (ionic polarizability)과 기공 형성으로 인한 박막 밀도의 감소로 유전상수 를 감소시키는 것으로 보고되어 있다[2,4].

연구에서는 $\mathrm{C}-\mathrm{V}$ 특성을 통하여 $\mathrm{SiOCH}$ 박막의 표면전하밀도를 분석하였으며, I-V 특성을 통하여 절연특성을 규명하였고, 열처리에 따른 특성의 변 화를 조사하였다. 


\section{2. 실 험}

본 연구에서는 p-type (100) Si 기판에 CCP 방식 의 $\mathrm{PECVD}$ 방법을 이용하여 $\mathrm{SiOCH}$ 박막을 증착 하였다. 사용한 PECVD 시스템은 $\mathrm{P}-5000$ 이며, 초 기 진공도를 $1 \times 10^{-6}$ Torr까지 배기하였다. 증착에 사용된 전구체는 실리콘과 탄소 원자를 함께 포함 하고 있는 BTMSM (Bistrimethylsilylmethane, $\left.\left(\left(\mathrm{CH}_{3}\right)_{3} \mathrm{Si}\right)_{2} \mathrm{CH}_{2}\right)$ 을 사용하였다. 상온에서 액체 형태 로 존재하는 $\mathrm{BTMSM}$ 을 버블러에 담아 아르곤 (Ar) 가스를 이송가스로 사용하여 전구체를 반응 챔버로 이동시켰으며, 또한 $\mathrm{SiOCH}$ 증착시 반응가 스로 산소 $\left(\mathrm{O}_{2}\right)$ 가스를 BTMSM 전구체와 혼합하 여 사용하였다. 박막 증착은 실온으로 하였으며 기 판온도를 $100{ }^{\circ} \mathrm{C}$ 로 맞추어 실시하였다. 작업 진공 도는 3.0 Torr를 유지하였고, 증착에 필요한 에너 지원으로 $13.56 \mathrm{MHz}$ 의 $\mathrm{RF}$ 를 $450 \mathrm{~W}$ 로 인가하였으 며, 샤워 헤드 (shower head)와 기판과의 거리는 반복된 실험을 통하여 $500 \mathrm{mils}$ (약 $12.7 \mathrm{~mm}$ )로 최적화하였다. 증착 변수로 이용한 $\mathrm{BTMSM}$ 전구 체의 유량비는 고유량에 대한 박막의 특성을 알아 보기 위하여 $42 \mathrm{sccm} \sim 60 \mathrm{sccm}$ 까지 $2 \mathrm{sccm}$ 씩 변화시켰으며, 반응 가스로 사용한 $\mathrm{O}_{2}$ 의 유량은 $60 \mathrm{sccm}$ 으로 일정하게 유지하였다. 실온에서 BTMSM 전구체 유량비에 따라 증착된 $\mathrm{SiOCH}$ 박 막의 후 열처리에 따른 전기적인 특성 영향을 조 사하기 위해서 열처리를 실시하였다. 열처리 온도 는 $200 \sim 500{ }^{\circ} \mathrm{C}$ 실험해 본 결과 $400 \sim 500{ }^{\circ} \mathrm{C}$ 사이에서 가장 안정적인 박막의 성질을 갖는 것으 로 판단됨에 따라 $450{ }^{\circ} \mathrm{C}$ 로 30 분 동안 진공 상태 에서 열처리를 실시하였다.

$\mathrm{SiOCH}$ 박막의 유전상수를 측정하기 위하여 400 $\mu \mathrm{m}$ 금속 $\operatorname{dot}$ 마스크를 이용하여 알루미늄 $(\mathrm{Al})$ 전 극을 구현한 $\mathrm{MIS}\left(\mathrm{Al} / \mathrm{SiOCH} / \mathrm{p}^{-} \mathrm{si}(100)\right)$ 구조의 커 패시터를 제작하여 정전용량-전압 $(\mathrm{C}-\mathrm{V})$ 특성을 측정하였다. $\mathrm{C}-\mathrm{V}$ 측정은 $\mathrm{HP} 4284 \mathrm{~A} 1 \mathrm{Mhz} \mathrm{LCR}$ meter를 이용하여 측정하였다. 또한 축적상태의 정 전용량 값과 두께 그리고 면적을 이용하여 $\mathrm{SiOCH}$ 박막의 유전상수 값을 계산하였다.

\section{3. 결과 및 고찰}

$\mathrm{SiOCH}$ 박막의 유전상수는 전자분극, 이온분극, 쌍극자 모멘트분극과 공간전하 분극에 의한 편극 으로 결정된다. 그러나 $\mathrm{SiOCH}$ 박막의 경우 비정질 구조로서 쌍극자 모멘트분극과 공간전하 분극에 의한 기여도는 0 에 가까운 값으로 거의 무시할 수 있다[5].
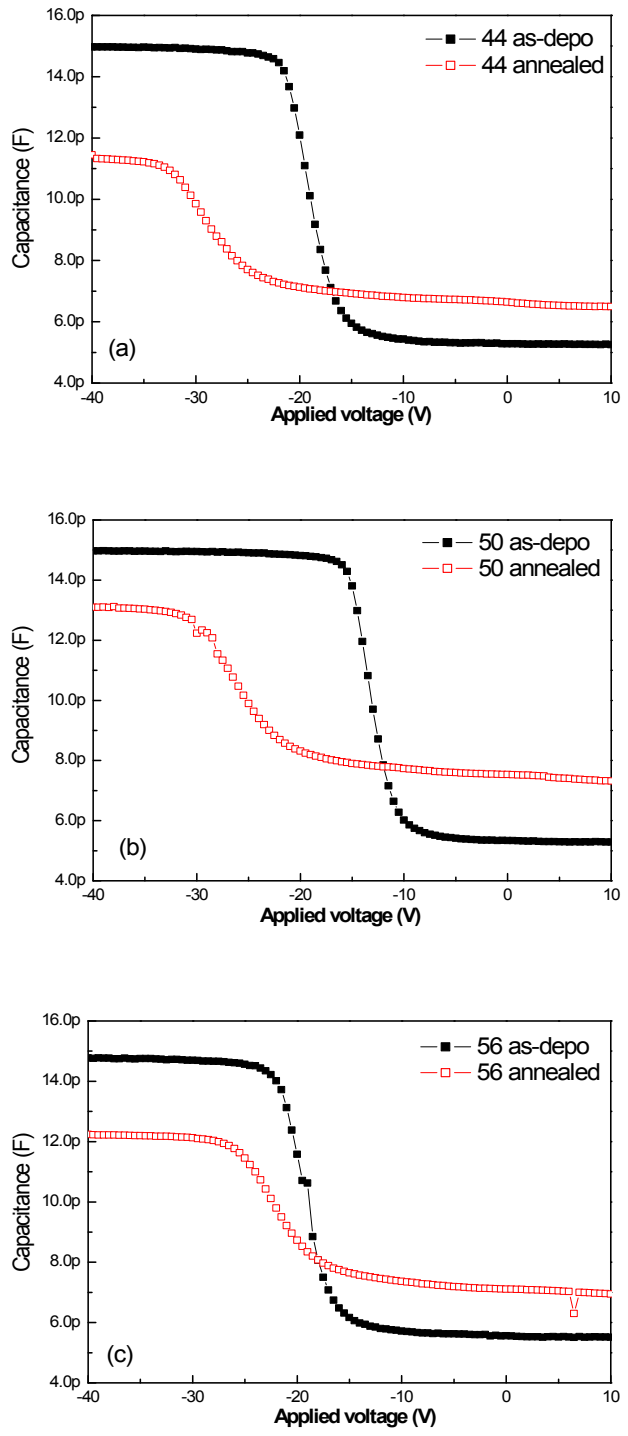

그림 1. BTMSM 유량에 대한 $\mathrm{C}-\mathrm{V}$ 특성 곡선 (1 MHz) (a) $44 \mathrm{sccm}$ (b) $50 \mathrm{sccm}$ (c) $56 \mathrm{sccm}$.

Fig. 1. Capacitance with BTMSM flow rates Vs applied voltage at $1 \mathrm{MHz}$ (a) 44 sccm (b) $50 \mathrm{sccm}$ (c) $56 \mathrm{sccm}$.

결국 $\mathrm{SiOCH}$ 박막의 유전상수에 영향을 주는 것 은 전자분극 및 이온분극에 의한 편극이다. 전자분 극의 변화는 굴절률의 변화와 밀접한 관련이 있으 며, 이온분극의 변화는 MIS구조 커패시터의 최대 
정전용량 값의 변화와 밀접하게 관련되어 있다. BTMSM 전구체에 의해 형성된 $\mathrm{SiOCH}$ 박막의 경 우 유전상수 기여 인자는 전자분극 보다 이온분극 에 의한 영향을 더 크게 받는다[6]. 따라서 $\mathrm{SiOCH}$ 박막의 이온분극에 의한 표면 전하를 분석하기 위 하여 $\mathrm{Al}$ 전극을 구현한 $\mathrm{MIS}(\mathrm{Al} / \mathrm{SiOCGH} /$ $\mathrm{p}-\mathrm{si}(100))$ 구조의 커패시터를 제작하였다. 그리고 $-40 \mathrm{~V} \sim 10 \mathrm{~V}$ 사이의 전압을 인가하여 $\mathrm{C}-\mathrm{V}$ 특 성을 얻었다. 음 (negative)의 전압이 인가된 $\mathrm{Al}$ 전극에 $\mathrm{p}$ 형 $\mathrm{Si}$ 반도체의 다수캐리어인 정공 (hole) 이 절연막과 $\mathrm{Si}$ 사이의 경계면으로 완전히 이동하 는 포화상태에서 전체 정전용량으로 식 (1)과 같은 근사적인 정전용량 $\left(\mathrm{C}_{\mathrm{i}}\right)$ 값으로 유전상수를 구하였 다. 여기서, $\mathrm{C}$ 는 정전용량, $\epsilon_{0}$ 는 진공에서의 유전 상수, $\epsilon_{r}$ 은 상대유전상수, $\mathrm{A}$ 는 전극의 면적, $\mathrm{d}$ 는 유전박막의 두께이다.

$$
C_{(\text {Total })}=\frac{C_{i} \cdot C_{s}}{C_{i}+C_{s}} \approx C_{i}=\frac{\epsilon_{r} \epsilon_{o} A}{d}
$$

그림 1에 각각 (a) 44, (b) 50, (c) $56 \mathrm{sccm}$ 의 BTMSM 유량에 대해 실온 증착된 $\mathrm{SiOCH}$ 박막의 $\mathrm{C}-\mathrm{V}$ 특성과 $450{ }^{\circ} \mathrm{C}$ 에서 30 분 동안 열처리된 시료 의 $\mathrm{C}-\mathrm{V}$ 특성을 비교하였다. 열처리 후 $44 \mathrm{sccm}$ 시료는 커패시턴스 최대값이 약 $4 \mathrm{pF}$ 정도 감소하 였고, $50 \mathrm{sccm}$ 시료는 약 $2 \mathrm{pF}$, 그리고 $56 \mathrm{sccm}$ 시료는 약 $3 \mathrm{pF}$ 감소하였다. 이것은 열처리 후 $\mathrm{p}-\mathrm{Si}$ 반도체 표면에 축적되는 양의 전하들이 전체 적으로 감소한 것으로 $\mathrm{SiOCH}$ 박막 저유전특성과 밀접한 관련이 있다. 또한 커패시턴스 최대값 $\left(\mathrm{C}_{\max }\right)$ 에서 최소값 $\left(\mathrm{C}_{\min }\right)$ 으로 변하는 $\mathrm{C}-\mathrm{V}$ 특성 곡 선 기울기의 늘어짐은 절연막 및 $\mathrm{Si}$ 반도체 계면 에 전하의 존재를 나타내며 평탄대 전압 (Flat band Voltage, $\mathrm{V}_{\mathrm{FB}}$ )에 영향을 주는 것으로 조사되 었다.

그림 1에 나타난 $\mathrm{MIS}$ 구조의 $\mathrm{C}-\mathrm{V}$ 특성 곡선을 미분한 결과를 그림 2에 나타내었다. 미분하여 얻 어진 피크의 위치를 $\mathrm{V}_{\mathrm{FB}}$ 로 정의한다. 실온 증착된 시료를 열처리 하였을 때 $44 \mathrm{sccm}$ 시료의 $\mathrm{V}_{\mathrm{FB}}$ 가 $-19.5 \mathrm{~V}$ 에서 $-29.5 \mathrm{~V}$ 로 이동하였으며, 피크의 면 적이 $49 \%$ 감소하였다. $50 \mathrm{sccm}$ 시료의 $\mathrm{V}_{\mathrm{FB}}$ 는 $-13.5 \mathrm{~V}$ 에서 $-28.0 \mathrm{~V}$ 로 이동하였으며, 피크의 면 적은 $40.5 \%$ 감소하였다. $56 \mathrm{sccm}$ 시료의 $\mathrm{V}_{\mathrm{FB}}$ 는 $-18.5 \mathrm{~V}$ 에서 $-22.5 \mathrm{~V}$ 로 이동하였으며 피크의 면적 은 $50 \%$ 감소하였다.
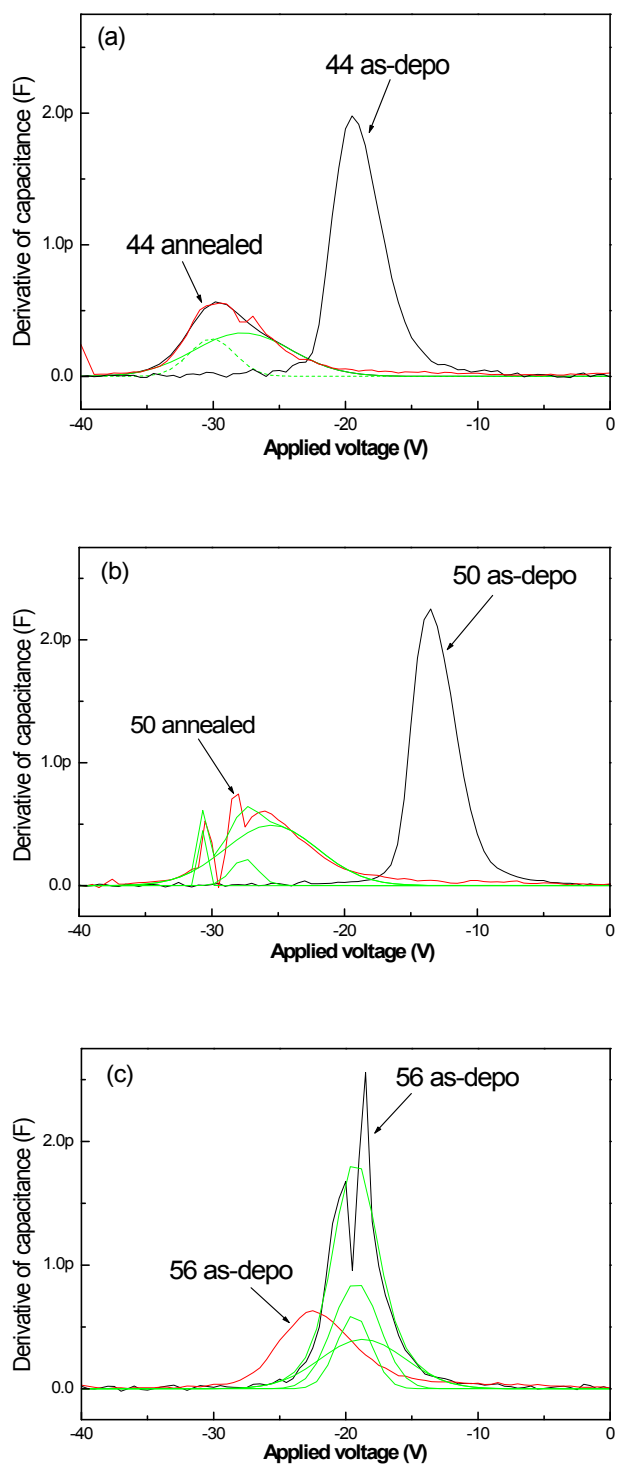

그림 2. BTMSM 유량에 대한 $\mathrm{SiOCH}$ 박막의 미 분된 $\mathrm{C}-\mathrm{V}$ 특성 (1 MHz) (a) $44 \mathrm{sccm}$ (b) $50 \mathrm{sccm}$ (c) $56 \mathrm{sccm}$.

Fig. 2. Derivatived Capacitance with BTMSM flow rates $\mathrm{Vs}$ applied voltage at $1 \mathrm{MHz}$ (a) $44 \mathrm{sccm}$ (b) $50 \mathrm{sccm}$ (c) $56 \mathrm{sccm}$.

열처리 후 피크의 위치가 더 큰 음의 방향으로 이동하는 것은 절연체와 $\mathrm{p}-\mathrm{Si}$ 계면에 양전하의 $\mathrm{CH}_{\mathrm{x}}{ }^{+}, \mathrm{H}^{+}$와 같이 쉽게 이동할 수 있는 이온성 불 순물이 감소하였기 때문이다. 이러한 계면 전하의 
감소는 $\mathrm{SiOCH}$ 박막의 유전상수를 감소시킬 수 있 으나, 계면 전하와 유전상수 사이에 비례관계는 갖 지 않는 것으로 조사되었다. 대칭성을 갖는 피크는 계면에 단일 전하가 존재하는 것으로, 만약 자유전 자가 존재하는 경우 인가된 전압에 의해 완전한 대칭성을 보이며 더 낮은 유전특성을 형성한다. 반 면 비대칭성 피크는 $\mathrm{CH}_{\mathrm{x}}^{+}, \mathrm{H}^{+}$와 같은 두 개 이상 의 복합 전하가 존재하는 것이며, 피크의 모양은 인가된 전압에 대응하는 전하의 종류와 그 양에 따라 결정된다. 이러한 복합 전하의 구조는 Gaussian peak Fitting으로 분해하여 나타내었다.

유량에 상관없이 열처리 후 피크 면적이 전체적 으로 감소한 것으로 나타났는데, 이것은 표면전하 밀도가 현저하게 감소한 것에 기인한다. 이러한 표 면전하밀도의 감소는 $\mathrm{SiOCH}$ 박막의 유전상수를 낮추는 주된 원인이 된다.

그림 3 에 각각의 유량에 대해 미분된 $\mathrm{C}-\mathrm{V}$ 특성 에서 얻어진 $\mathrm{V}_{\mathrm{FB}}$ 의 변화를 나타내었다. 실온층착 시료의 평균 $\mathrm{V}_{\mathrm{FB}}$ 는 $-15.4 \mathrm{~V}$, 표준편차는 \pm 3.3 이며 전구체 유량의 증가에 따라 음의 전압으로 조금씩 이동하는 경향성을 보인다. 열처리 후 평균 $\mathrm{V}_{\mathrm{FB}}$ 는 $-24.4 \mathrm{~V}$, 표준편차는 \pm 3.3 으로 더 큰 음의 방향으 로 이동하였으며 전구체 유량의 증가에 따라 양의 전압으로 조금씩 이동하는 경향을 보인다. 특히 열 처리 후 전체적인 $\mathrm{V}_{\mathrm{FB}}$ 가 더 큰 음의 방향으로 이 동하는 것은 절연체와 $\mathrm{p}-\mathrm{Si}$ 반도체 계면에 양전하 의 $\mathrm{CH}_{\mathrm{x}}{ }^{+}, \mathrm{H}^{+}$와 같이 쉽게 이동할 수 있는 이온성 불순물이 감소했기 때문이다. 그러나 이러한 계면 전하의 존재는 $\mathrm{SiOCH}$ 박막의 유전상수와 비례관

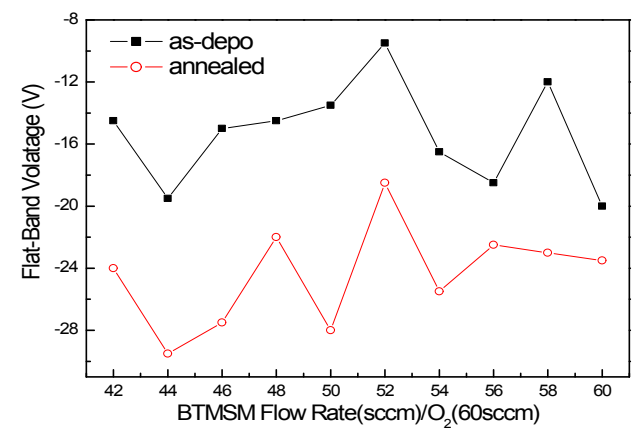

그림 3. 다양한 BTMSM 유량변화에 대한 평탄 대 전압의 이동.

Fig. 3. Shift of Flat-band voltage with various BTMSM flow rates as-deposition and annealed.
계는 갖지 않는 것으로 조사되었다.

그림 2에 나타난 피크의 최대 높이를 최대 피크 폭으로 나눈 비율을 그림 4에 $\mathrm{Q}$ (Quality factor) 로 나타내었다. $\mathrm{Q}$ 값은 $\mathrm{SiOCH}$ 박막내의 유동성 이온들의 집단운동 특성을 나타내는 지수로 $\mathrm{Q}$ 값 이 클수록 그림 3 의 피크는 높이가 높고 상대적으 로 폭은 좁은 특성을 보인다. 완전히 상이한 값을 갖는 $60 \mathrm{sccm}$ 시료를 제외하고, 실온 증착한 시료 의 평균 $\mathrm{Q}$ 값은 $0.44 \mathrm{pF} / \mathrm{V}$, 표준편차는 \pm 0.19 이며, 열처리 후 각각 $0.17 \mathrm{pF} / \mathrm{V}, \pm 0.15$ 로 감소하였다. 열처리 후의 시료가 더 낮은 $\mathrm{Q}$ 값을 갖는 것은 열 처리 후 반도체 표면전하밀도의 감소에 따라 더 낮은 유전특성을 형성하는 것을 의미한다.

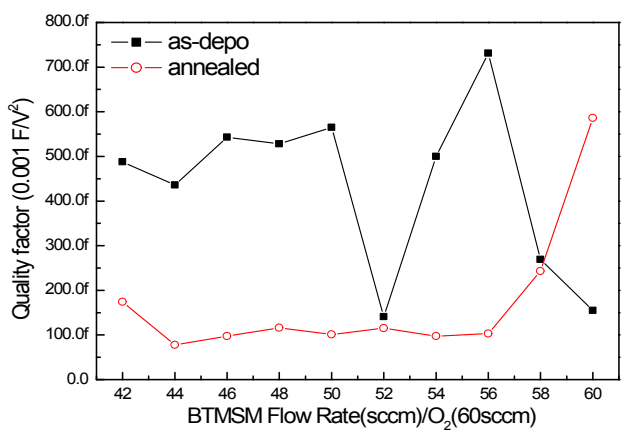

그림 4. BTMSM 유량변화에 대한 미분된 $\mathrm{C}-\mathrm{V}$ 피크의 민감성.

Fig. 4. Quality factor of derivatived $\mathrm{C}-\mathrm{V}$ peak with various BTMSM flow rates.

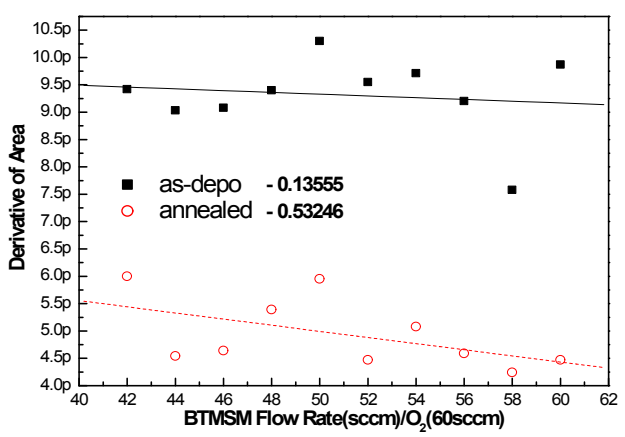

그림 5. BTMSM 유량과 미분된 $\mathrm{C}-\mathrm{V}$ 피크 면적 의 상관관계.

Fig. 5. Correlation between BTMSM flow rates and derivatived $\mathrm{C}-\mathrm{V}$ peak area. 
전구체 유량과 미분된 $\mathrm{C}-\mathrm{V}$ 피크 면적의 상관관 계를 그림 5 에 나타내었다. 피크 면적의 변화는 $\mathrm{p}-\mathrm{Si}$ 반도체 표면전하밀도의 변화를 의미한다. 실 온증착 시료의 상관계수 $\mathrm{R}$ 은 -0.13555 이고, 열처 리 후 -0.53246 으로, 열처리 후 전구체 유량과 표 면전하밀도가 더 큰 반비례 관계를 갖는 것으로 나타났다. 이것은 전구체 유량 증가 및 열처리에 따라 표면전하밀도가 감소하며 $\mathrm{SiOCH}$ 박막의 유 전상수를 낮추는 주된 요인으로 분석되었다.
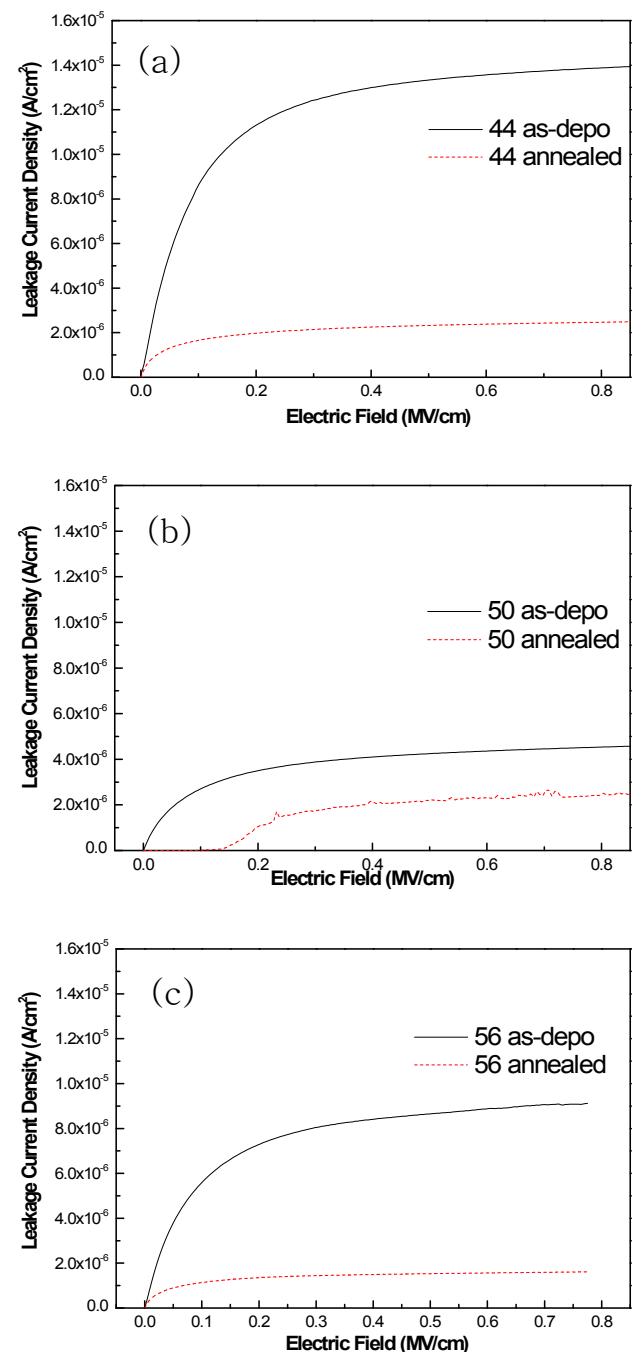

그림 6. BTMSM 유량에 대한 누설전류밀도 (a) $44 \mathrm{sccm}$ (b) $50 \mathrm{sccm}$ (c) $56 \mathrm{sccm}$.

Fig. 6. Leakage Current Density with various BTMSM flow rates of $\mathrm{SiOCH}$ film (a) $44 \mathrm{sccm}$ (b) $50 \mathrm{sccm}$ (c) $56 \mathrm{sccm}$.
그림 6에 각각 (a) 44, (b) 50, (c) $56 \mathrm{sccm}$ 전구 체 유량에 대한 전류밀도-전계 $(\mathrm{J}-\mathrm{E})$ 특성을 나타 내었다. HP4156A 반도체 파라미터 분석기를 이용 하여 $0 \mathrm{~V} \sim 20 \mathrm{~V}$ 사이의 전압을 인가하여 누설 전류를 측정하였으며 형성된 $\mathrm{SiOCH}$ 박막의 두께는 약 1500 $2000 \AA$ 이다. 열처리 후 44, 50 및 56 $\mathrm{sccm}$ 시료의 누설전류밀도가 각각 $82.4 \%, 46 \%$ 그리고 $82.8 \%$ 감소한 것으로 나타났다. 이러한 결과는 열처리 후 $\mathrm{p}-\mathrm{Si}$ 반도체 표면전하밀도의 감소 와 밀접한 관련이 있으며, 열처리에 의하여 낮은 유 전특성이 형성된 것으로 분석된다. 특히 44,50 , 및 56 $\mathrm{sccm}$ 시료는 2.0 부근의 낮은 유전상수를 가지면서도 상대적으로 낮고 안정된 누설전류특성을 보였다. 그러나 누설전류밀도와 $\mathrm{SiOCH}$ 박막의 유전특성 사이에 비례관계는 갖지 않는 것으로 조사되었다.

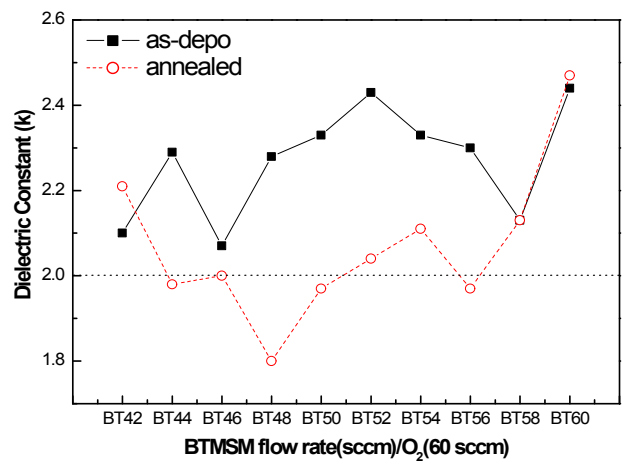

그림 7. BTMSM 유량변화에 대한 유전상수의 변화.

Fig. 7. Dielectric constant of $\mathrm{SiOCH}$ film with various BTMSM flow rates.

그림 7은 BTMSM 전구체 유량 변화에 대한 유전 상수의 변화를 나타내었다. 실온 증착된 $\mathrm{SiOCH}$ 박막 의 평균 유전상수는 2.27 , 표준편차는 \pm 0.13 이었으나 열처리 후 각각 $2.07, \pm 0.18$ 로 감소하였다. 이것은 열 처리에 의해 감소된 표면전하밀도가 전체 유효 이온 분극성을 감소시켜 낮은 유전상수 형성에 결정적인 영향을 주기 때문이다[7]. 또한 46, $58 \mathrm{sccm}$ 을 제외 한 실온 증착된 시료는 전구체 유량이 증가함에 따라 유전상수가 상승하는 경향성을 보이며, 열처리 후에 42, 58, $60 \mathrm{sccm}$ 을 제외한 나머지 시료는 전체적으 로 2.0 부근의 낮은 유전상수를 갖는 것으로 나타났 다. 그러나 전구체의 유량과 $\mathrm{SiOCH}$ 박막의 유전특성 사이에 비례관계는 갖지 않는 것으로 조사되었다. 


\section{4. 결 론}

$\mathrm{PECVD}$ 방식으로 BTMSM의 유량을 $42 \sim 60$ $\mathrm{sccm}$ 으로 변화시켜가며 $\mathrm{SiOCH}$ 박막을 형성하였 다. $\mathrm{C}-\mathrm{V}$ 특성을 통하여 $\mathrm{SiOCH}$ 박막의 표면전하 밀도를 분석하고 유전상수를 구하였다. 또한 누설 전류를 측정하여 절연특성을 분석하였다. 실온 증 착된 $\mathrm{SiOCH}$ 박막의 유전상수는 2.27 , 표준편차 \pm 0.13 이며, 열처리 후 유전상수는 2.07 , 표준편차 \pm 0.18 로 감소하였다. 또한 누설전류밀도 역시 열처 리에 의해서 $60 \%$ 이상 현저하게 감소하였다. 이 러한 결과는 열처리에 의해 감소된 표면전하밀도가 $\mathrm{SiOCH}$ 박막의 전체 유효 이온 분극성을 감소시켜 유전상수를 낮추는 것으로 분석되었다.

\section{참고 문헌}

[1] W. Y. Chen, S. K. Gupta, and M. A. Breuer, "Analytical models for crosstalk excitation and propagation in VLSI circuits", IEEE, Vol. 21, No. 10, p. 1117, 2002.

[2] M. R. Baklanov and K. Maex, "Porous low dielectric constant materials for microelectr- onics", Phil. Trans. R. Soc., Vol. 364, p. 201, 2006.

[3] K. Maex, M. R. Baklanov, D. Shamiryan, F. Iacopi, S. H. Brongersma, and Z. S. Yanovitskaya, "Low dielectric constant materials for microelectronics", J. Appl. Phys., Vol. 93, No. 11, p. 8793, 2003.

[4] Y. H. Kim, "Deposition and characterization of low-dielectric-constant SiOC thin films for interlayer dielectrics of multilevel interconnection", Ph. D. Dissertation, Seoul National University, 2002.

[5] S. M. Han and E. S. Aydil, "Reasons for lower dielectric constant of fluorinated $\mathrm{SiO}_{2}$ films", J. Appl. Phys., Vol. 83, No. 4, p. 2172, 1998.

[6] M. S. Kim, C. S. Hwang, and H. B. Kim, "Dielectric characteristic through 2D-correlation analysis of $\mathrm{SiOCH}$ thin film deposited by BTMSM $/ \mathrm{O}_{2}$ high flow rates", J. of KIEEME (in Korean), Vol. 21, No. 6, p. 544, 2008.

[7] A. Grill and V. Patel, "Ultra low-k dielectrics prepared by plasma-enhanced chemical vapor deposition”, Applied Physics letters, Vol. 79, No. 6, p. 803, 2001. 